\title{
VIEWPOINTS
}

\section{Circular Economy and Environmental Recovery in the Post- Pandemic Period}

\author{
Shahino Mah Abdullah*
}

During the COVID-19 pandemic, there has been a substantial rise in plastic pollution. Discarded masks and gloves have been found in various cities, streets, sewers, rivers and seas, owing to people who take environmental cleanliness for granted. People must now play their part as responsible citizens in restoring the environment in the post-pandemic period. Individuals and industries that practise environmental stewardship can avoid the post-pandemic 'rebound effect', preserving the ecological balance. Refraining from polluting the environment will help to maintain the existing natural equilibrium. The necessity of preserving environmental balance is highlighted in the Qur'an: "And the Firmament has He raised high, and He has set up the Balance (of Justice), in order that ye may not transgress (due) balance" (55:7-8). In fact, Islam has made environmental stewardship a responsibility in life: "And do no mischief on the earth after it has been set in order, that will be best for you, if ye have Faith" (7:85). This illustrates how a person's care of the environment is linked to their moral reasoning and beliefs, especially during the challenging period of the pandemic and thereafter.

Post-pandemic environmental recovery requires the coordinated involvement of all parties. The least we can do is avoid polluting, while the most we can do is voluntarily eliminate all forms of pollution. This time, strategies to reduce waste cannot rely just on the efforts of government and non-governmental organisations to raise awareness and put enforcement into action, but also on manufacturers to produce good re-usable masks and gloves. This measure requires manufacturers to 'rethink' before making product, to go beyond the previous $3 \mathrm{R}$ practice outlined for consumers. A 'rethink' for consumers may imply an understanding of how to properly dispose of used items, while for manufacturers it requires the making of products that will not harm the environment. Eco-friendly antibacterial face masks, biodegradable gloves, and compostable shields, for example, should be among new innovative products. As is usual in business, the most crucial aspect is that manufacturers make all of these products affordable to consumers of various financial backgrounds. It is, 
of course, a challenge to produce high-quality products at affordable prices, but it is the task and responsibility of manufacturers to consider it, in accordance with the demand to 'rethink' for the sake of the environment.

Expanding the 3Rs will help to ensure ecological sustainability. 'Rethink', as previously suggested, can be added, as could refuse, repurpose, and rot, transforming the 3Rs into 7Rs (rethink, refuse, reduce, repurpose, reuse, recycle and rot). The first of the three Rs, 'Reduce', demands the usage of reusable products and a reduction in the quantity of used resources such as water and energy. Second, 'Reuse', can be applied to using single items until they are worn out, as long as they are safe. Third, 'Recycle', allows products to be reused under particular conditions, reducing the need for new materials. The additional Rs begin with 'Refuse', which simply means avoiding extravagance or refraining from unnecessary buying. 'Repurpose' is similar to reuse, but with a creative new concept, while 'Rot' focuses on biodegradable waste that can be returned to the soil to prevent GHG emissions, rather than dumping everything into landfill. There can be other Rs as long as they support environmental sustainability. For example, some may add Repair, Re-gift, and Recovery, making ten combinations instead of seven or three.

While the majority of these practices focus on the consumers' responsibility to manage their waste, there must also be a set of standards that manufacturers and the private sector should comply with in order to manage waste properly. To guarantee proper waste management, both consumers and manufacturers must work together. There are also 7Rs for manufacturers and the private sector known as the 'Circular Economy' model, which consists of 'rethink', 'reduce', 'reuse', 'repair', 'refurbish', 'recover', and 'recycle'. This model ensures that materials, components, and products are always at their best in terms of utility and value, at all times. A circular economy takes an alternative approach to traditional business models, which are characterised by linear economic activities that normally begin with resource utilisation and finish with waste. The conventional economic system of 'take-make-waste' continues to deplete natural resources via the production of unsustainable products, while also leading to a rise in landfill. A circular economy avoids unsustainable resource consumption and allows the regeneration of natural systems.

In the 7Rs, 'Rethink' prompts manufacturers to be mindful of resource utilisation and waste production. Their business models should address the issue of depleting resources and waste avoidance. One of the alternatives is to adopt a sharing economy, which uses fewer resources by promoting shared ownership of products. Second, a 'Reduce' mindset encourages manufacturers to use lean design concepts while also prolonging product life spans. Redesigning a product allows for the use of minimal resources and avoidance of waste. 'Reduce' in 
this sense can also refer to making a product that will last longer. Third, the 'Repair' feature allows manufacturers to keep products and use them for a much longer period of time. The 'Repair' feature is also applicable to consumers who own a product and keep it in good condition for their own use. These measures not only save money but also benefit the environment in the long run. Fourth, the term 'Reuse' refers to the act of transferring a used product in good condition to another user, such as through a second-hand marketplace. It can help manufacturers by allowing them to maintain the quality of their equipment while consumers get a low-cost and well-maintained used product. This will also save the environment by minimising waste.

Following on from this, the 'Refurbish' feat ure will enable the transformation of used products into new ones with improved design or performance. This can refer to the process of upcycling old products by giving them a new lease of life, either for personal use or for resale. When a product is beyond repair or refurbishment, however, it is placed in the 'Recycle' category. Here, a product must be dissembled before it can be recycled. Some parts, such as the gold in electronic components, are still valuable enough to recycle without degrading their quality. Most people believe that the measures listed above are part of the process of 'Recovering' old items. This is not incorrect, but what 'recover' also signifies here is using non-recycled parts that cannot be repaired, refurbished, or recycled for energy generation using waste-to-energy processes such as combustion and gasification. This energy can then be re-used by industries. Within this circular economy model, nothing will be wasted, and there will be no more garbage stockpiling in landfills. In fact, existing garbage can be discarded using the above principles, culminating in energy conversion. In this way, the 7Rs can solve both current and previous environmental issues related to pollution stemming from improper waste disposal. A circular economy will benefit the environment by cleaning up, creating jobs through the recovery process, and reducing resource consumption by 'cascading materials' from existing products. It may be the finest strategy for manufacturers to conserve the environment, save money, and restore employment after the pandemic.

\section{Notes}

* Shahino Mah Abdullah is a Research Fellow at the International Institute of Advanced Islamic Studies (IAIS) Malaysia. He can be contacted at: shahino@, iais.org.my. 